Portland State University

PDXScholar

8-6-2020

\title{
The Development of Immigrants in Education
}

Kayla R. Guerrero

Portland State University

Follow this and additional works at: https://pdxscholar.library.pdx.edu/honorstheses

Part of the Developmental Psychology Commons

Let us know how access to this document benefits you.

Recommended Citation

Guerrero, Kayla R., "The Development of Immigrants in Education" (2020). University Honors Theses.

Paper 926.

https://doi.org/10.15760/honors.948

This Thesis is brought to you for free and open access. It has been accepted for inclusion in University Honors Theses by an authorized administrator of PDXScholar. Please contact us if we can make this document more accessible: pdxscholar@pdx.edu. 
The Development of Immigrants in Education

by

Kayla Guerrero

An undergraduate honors thesis submitted in partial fulfillment of the requirements for the

degree of
Bachelor of Arts
in
University Honors
and
Psychology

Thesis Advisors

Maciel M. Hernandez, Ph.D. and Rebecca Summer, Ph.D.

Portland State University 


\begin{abstract}
Being an essential part of American community, immigrants face several challenges as they adjust to life away from their home country. Many of those challenges begin when immigrant students start school in the United States education system. This exploratory research investigates the school experiences of immigrants and whether or not they were supported by their peers, teachers, parents, and community and how that influenced their development. Adult immigrants will reflect back on their education experience through interviews in order for the researcher to contribute a new foundation for immigrant student development research from the perspective of actual immigrants. This will show how schools can better support their immigrant students in order to optimize their psychological development. Due to COVID-19, the interviews were postponed. This thesis will include the methodology and predicted results.
\end{abstract}


The Development of Immigrants in Education

While immigrants are a beneficial and important part of American society, immigrant students are more likely to grow up in poverty (Coppel, Dumont, \& Visco, 2001; Hernandez, Takanishi, \& Marotz, 2009; Suárez-Orozco et al., 2010). On top of that, immigrants are also more likely to face challenges in documentation status, language, and discrimination (Hernandez \& Cervantes, 2011). Because of all these disadvantages many immigrants have to deal with, it makes sense to aid immigrant students during their most vulnerable developmental period while they attend school. Unfortunately, not all schools have the extra support needed to optimize immigrant students' development, even though it is necessary (Suarez-Orozco, Motti-Stefanidi, Marks, \& Katsiaficas, 2018). Studies have researched different ways of helping immigrant students adjust and thrive in their new schools. For example, strong community and support systems aid in immigrant students' development and in turn have supported their school achievement (Dearing et al., 2016). Additionally, maintaining strong relationships with peers, family, and the community are factors in prosperity and school achievement of immigrant students (Suárez-Orozco et al., 2010). In another study, researchers found that genuine friendships helped cancel out the negative impact of exclusiveness, ignorance of culture, feelings of non-belongingness, and language discrimination against immigrant children (Hajisoteriou, Karousiou, \& Angelides, 2017). This study also showed that teaching about the cultures of immigrant students in collaborative ways (versus folkloric) helped not only immigrant children, but also their non-immigrant classmates understand different cultures (Hajisoteriou, Karousiou, \& Angelides, 2017). Continually, immigrant children benefit from efforts and programs designed to optimize their development in schools, especially when their home culture is included. 
Because of COVID-19, all in-person research was suspended and in order to fully protect the participants from breaches of confidentiality that may occur through online video meetings, this study has been postponed. This thesis will cover the methods and future research steps to be taken.

The current study will investigate the perspectives of adult immigrants who have experienced education in the United States through qualitative methods. This will be an exploratory research project. The researcher hopes to create a new foundation for research concerning immigrant students that will help optimize their development.

Both documented and undocumented immigrants will be able to participate in the study, so some of the extra precautions, recommended by the Institutional Review Board at Portland State University, were taken in order to protect undocumented immigrants. These include using verbal consent, using pseudonyms, keeping study materials secure on a password protected computer, and destroying interview recordings a year after research is done. The investigator will not be directly asking the documentation status of the participants, but that does not mean the participants will not divulge their status during the interview on their own terms. These steps are necessary to protect undocumented immigrants who, although are not explicity defined as a vulnerable popultion, fit the criteria of needing extra protections. Otherwise, undocumented immigrants could have risked deportation if there were to be a breach of confidentiality, thus making these extra steps necessary. (Hernández, Nguyen, Casanova, Suárez-Orozco, \& Saetermoe, 2013).

This study will help immigrants gain greater representation in research because there will be first-hand information about the needs and desires of immigrant students. Their voices will be 
heard and hopefully considered in future research. The main purpose is to gather data that will guide educators to best support their immigrant students and optimize their development. Once the thesis is complete, other researchers will be able to look back and reframe their research for future studies around the perspectives of actual immigrants and consider their experiences in creating programs to aid their development.

\section{Methods}

\section{Participants}

The investigator will interview 5 participants in this qualitative study. The participants will be adult (18 or older) immigrants (foreign born or have at least one parent who is foreign born) who entered the United States school system before the fifth grade. They will vary in age, race, culture, and country of origin. Each participant will complete an approximately 60 minute interview discussing their immigrant experience in school. This study will include both documented and undocumented immigrants. The investigator hopes to recruit immigrants of varying countries of origin, cultures, races, ages, and genders.

\section{Assessments and Measures}

This is a qualitative study where the researcher will gain knowledge through first-hand accounts or interviews. The interviews will be coded. Coding is a qualitative method that involves labeling pieces of the gathered data in order to compare and contrast and find patterns within the research (Gibbs, 2007; Lofland \& Lofland, 1995; Miles \& Huberman, 1994; Taylor \& Bogdan, 1998). With the information found through this study, the researcher will layout areas that need to be improved in schools and areas that educators should keep in order to help immigrant students adjust in school, therefore optimizing their development. 


\section{Procedure}

Participants will be recruited for this study via email. The investigator will send the email to clubs and groups at Portland State University to pass along to potential participants. The interested individuals will email the researcher and schedule an interview date and time or they will ask for more information or any clarifying questions they may have.

The interviews will be held in-person at a location such as Smith Memorial Student Union or a location of the participants choice such as a study room in the library or a local coffee shop. The interviews will last approximately 60 minutes. Each interview will consist of one participant and one researcher. In the interview, the researcher will ask the participants questions about their experience in school as an immigrant. More specifically, the researcher will ask what troubles they had, what programs or actions their teachers took that helped them adjust to school in the United States.

The interviews will be digitally recorded and then manually transcribed into text. Then, it will be coded to find common themes and discussed in the context of immigrant psychological development. After it is coded, the data will be analyzed by the researcher as well as comparing and contrasting to each interview.

To protect possible undocumented participants, the researcher will waive the informed consent to verbal consent (instead of a written signature). This will remove a possible piece of identifiable information (the signature) if the research were to have a breach of confidentiality. Without the signature, there is no connection to the particpants' identity, therefore, protecting possible undocumented immigrants from exposure of their immigration status if there were to be 
a breach of confidentiality, such as files getting hacked, computer getting stolen and then broken into, et cetera.

Each participant who will complete an interview will be given a pseudonym. This is also to protect the participants from having identifiable information present in the research notes. The digitally recorded interviews, the transcripts, and all other research materials will be kept on a password protected computer that only the researcher has access to. After one year of each interview, the recordings will be deleted.

\section{Questions}

First, the interviewer will ask the participants the positive aspects of their education experience, such as who gave them support, or if their school implemented any programs to help them adjust. Next, the interview will ask about any challenges the participants faced. This could include discussing unwelcomeness or uncomfortableness, needs not being met, racism, or bullying. Another question asked will be covering communication. Did they know the host language before they entered school? Were they placed in an ESL class? The interviewer will ask what kind of support or advice they would give to new immigrant students if they were to volunteer in a classroom. Lastly, the interviewer will ask what changes would have made their experience and transition a more positive one in their school.

\section{Discussion}

\section{Predicted Outcomes}

While the responses in the interviews may vary, the researcher predicts that friendships, family, and community would be a main contributor to a positive development. Additionally, those schools that did have programs especially for immigrant students would also greatly benefit the 
students'. Teachers who took an extra step and went out of their way to support and ease the transition of immigration would also be a positive influence on development.

Predicted challenges would include experiences unwelcomeness and getting excluded from not just peer groups and community events, but also from American culture, knowing how the school system works, and various resources that would help the students' and their families. Bullying may also be another common theme and immigrants may be bullied for their lack of English language skills, the food they bring to lunch, their appearance and clothing choices, and other cultural differences. The investigator predicted that immigrants of color would also experience racism, therefore dealing with extra exclusiveness, lack of access to resources, and more bullying.

The changes the participants would like to see would most likely be extra support in their transition and making schools more welcoming to immigrants.

A common predicted theme might be educating non-immigrant students about immigrants and including a diverse, multicultural curriculum. If there are students who celebrate Eid then there should be just as much attention on learning about it and activities surrounding it as Christmas in schools. The more understanding there is between all students, teachers, families, and communities, the less challenges the immigrant students will likely have to encounter.

\section{Future research}

Future research studies may want to isolate cultures, races, ages, or genders and see how they interact with the immigrant's experience. For example, there may be a great difference in school experiences between a British immigrant and a Nigerian immigrant regarding racism and language barriers to name a few. Another study that would supplement this one would be 
interviewing current students from when they first immigrated (or began school) and a few years later, comparing their progression and noting differences in their attitudes towards their schooling. It also may be beneficial to look at existing curriculums and see if there are any units that would help immigrant students. Additionally, interviewing teachers would help researchers get another perspective to the narrative. Perhaps there are some teachers who were not able to add a cultural unit to their curriculum, but went out of their way to give immigrant children extra support. There is much to explore in this area of research and each pathway would help immigrant students in their transition to education in the United States.

\section{Conclusion}

Although research had to be postponed, this study has much potential to contribute to the existing knowledge of immigrant development. Whether or not immigrants thought their school helped them, there is still a need for improvement. Schools need to be constantly working to support their immigrant students just as much as their non-immigrant students. The more effort, the more likely it will have a more positive effect on immigrant students' development. 


\section{References}

Abo-Zena, M. M. (2018). Supporting Immigrant-Origin Children: Grounding Teacher Education in Critical Developmental Perspectives and Practices. Teacher Educator, 53(3), 263-276. doi: https://doi.org/10.1080/08878730.2018.1457751

Blanchet-Cohen, N., \& Reilly, R. C. (2017). Immigrant children promoting environmental care: Enhancing learning, agency and integration through culturally-responsive environmental education. Environmental Education Research, 23(4), 553-572.

doi:http://dx.doi.org/10.1080/13504622.2016.1153046

Coppel, J., Dumont, J., \& Visco, I. (2001). Trends in immigrant and economic consequences. (Working Paper No. 284). Paris, France: Organisation for Economic Co-operation and Development.

Dearing, E., Walsh, M., Sibley, E., Lee-St.John, T., Foley, C., \& Raczek, A. (2016). Can Community and School-Based Supports Improve the Achievement of First-Generation Immigrant Children Attending High-Poverty Schools? Child Development, 87(3), 883-897. https://search.library.pdx.edu/permalink/f/eqsjiv/TN_wj10.1111/cdev.12507

Gibbs, G. R. (2007). Qualitative Research kit: Analyzing qualitative data. London, England: SAGE Publications, Ltd doi:https://doi.org/10.4135/9781849208574

Gratier, M., Greenfield, P. M., \& Isaac, A. (2009). Tacit Communicative Style and Cultural Attunement in Classroom Interaction. Mind, Culture \& Activity, 16(4), 296-316. https://doi.org/10.1080/10749030903210070 
Hajisoteriou, C., Karousiou, C., \& Angelides, P. (2017). Mapping cultural diversity through children's voices: From confusion to clear understandings. British Educational Research Journal, 43(2), 330-349. doi:http://dx.doi.org/10.1002/berj.3266

Hernandez, D. J., \& Cervantes, W. D. (2011). Children in immigrant families: Ensuring opportunity for every child in America. New York, NY: Foundation for Child Development.

Hernandez, D. J., Takanishi, R., \& Marotz, K. G. (2009). Life circumstances and public policies for young children in immigrant families. Early Childhood Research Quarterly, 24, 487-501. doi:10.1016/j.ecresq.2009.09.003

Hernández, M., Nguyen, J., Casanova, S., Suárez-Orozco, C., \& Saetermoe, C. (2013). Doing No Harm and Getting It Right: Guidelines for Ethical Research with Immigrant Communities. New Directions for Child and Adolescent Development, 2013(141), 43-60. DOI:10.1002/cad

Isik-Ercan, Z. (2012). "I Go to School Six Days a Week": The Role of Cultural and Religious Practices Within Hybrid Turkish-American Communities in Supporting Academic and Socioemotional Growth. Childhood Education, 88(5), 292-297.

Lofland, J, and Lofland, L. H. (1995). Analyzing Social Settings: A Guide to Qualitative Observation and Analysis. Wadsworth Publishing Company: Belmont, CA

Marsh, K., \& Dieckmann, S. (2017). Contributions of playground singing games to the social inclusion of refugee and newly arrived immigrant children in australia.Education 3-13, 45(6), 710-719. doi:http://dx.doi.org/10.1080/03004279.2017.1347128

Miles, M. B., and Huberman, M. A. (1994). Qualitative Data Analysis 
Suárez-Orozco, C., Gaytán, F. X., Bang, H. J., Pakes, J., O’Connor, E., \& Rhodes, J. (2010). Academic trajectories of newcomer immigrant youth. Developmental Psychology, 46(3), 602-618. http://dx.doi.org/10.1037/a0018201

Suárez-Orozco, C., Motti-Stefanidi, F., Marks, A., \& Katsiaficas, D. (2018). An integrative risk and resilience model for understanding the adaptation of immigrant-origin children and youth. The American Psychologist, 73(6), 781-796. DOI:10.1037/amp0000265

Taylor, S.J. and Bogdan, R. (1998). Introduction to Qualitative Research Methods. Wiley and Sons: Hoboken, NJ. 


\section{Human Research Protection Program Notice of Exempt Certification}

February 20, 2020

Dear Investigator,

The PSU Institutional Review Board (IRB) reviewed the following submission:

\begin{tabular}{|l|l|}
\hline Investigator(s) & Rebecca Summer / Kayla Guerrero \\
\hline HRPP \# & $196745-18$ \\
\hline Title & The Development of Immigrant Students in Education \\
\hline Funding Agency / Kuali \# & N/A \\
\hline Determination Date & 02/20/2020 \\
\hline Expiration Date & N/A \\
\hline Review Category(ies) & Exempt: \# 2 \\
\hline
\end{tabular}

The IRB determined this study qualifies as exempt and is satisfied the provisions for protecting the rights and welfare of all subjects participating in research are adequate. The study may proceed in accordance with the plans submitted (HRPP Forms enclosed). Please note the following ongoing Human Research Protection Program (HRPP) requirements:

Changes to Study Activities: Any changes to the study must be submitted to the HRPP for review and determination prior to implementation.

Unanticipated Problems or Adverse Events: Notify the HRPP within 5 days of any unanticipated problems or adverse events that occur as a result of the study.

Study Completion: Notify the HRPP when the study is complete; the HRPP will request annual updates on the study status. Study materials must be kept for at least three years following completion.

Compliance: The PSU IRB (FWA00000091; IRB00000903) and HRPP comply with 45 CFR Part 46, 21 CFR Parts 50 and 56, and other federal and Oregon laws and regulations, as applicable.

If there are any questions, please contact the HRPP at psuirb@pdx.edu or call 503-725-5484.

Sincerely,

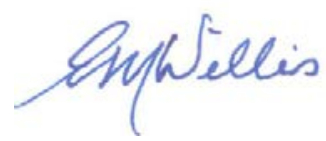

EM Willis, CIP, HRPP Administrator

Research Integrity \& Compliance 


\section{Human Research Protection Review \\ FORM 1: OVERVIEW \& PRE-SCREENING}

\section{SECTION 1: PROJECT OVERVIEW}

A. Project Title: The Development of Immigrant Students in Education

B. Study Lead: $\square$ Faculty Investigator $\bigotimes$ Student Investigator with Faculty Advisor

C. Investigator(s):

\begin{tabular}{|c|c|c|c|c|c|}
\hline Name & $\begin{array}{c}\text { Department } \\
\text { or Other } \\
\text { Affiliation }\end{array}$ & Email & $\begin{array}{c}\text { PSU } \\
\text { Affiliation }\end{array}$ & Project Role & $\begin{array}{c}\text { CITI } \\
\text { Training } \\
\text { Date* }\end{array}$ \\
\hline Rebecca Summer & $\begin{array}{l}\text { Urban } \\
\text { Honors } \\
\text { College }\end{array}$ & $\begin{array}{l}\text { rebeccasummer@p } \\
\text { dx.edu }\end{array}$ & PSU Employee & Principal Investigator & $10 / 30 / 19$ \\
\hline Kayla Guerrero & $\begin{array}{l}\text { Urban } \\
\text { Honors } \\
\text { College/Psyc } \\
\text { hology } \\
\end{array}$ & ukayla@gmail.com & PSU Student & Student Investigator & 10/29/19 \\
\hline & & & & & \\
\hline & & & & & \\
\hline & & & & & \\
\hline
\end{tabular}

*Application will not be processed until the PI, Co-I, Student Investigator or other Key Personnel listed have completed CITI Training.

D. Student Investigator: A faculty advisor MUST be identified above.

Is this project the subject of student's master's thesis or dissertation?

$\square$ Yes $\bigotimes$ No

E. Funding: Is the proposed project funded through external funding source(s)? $\square$ Yes $\square$ No List Funding Source(s):

Provide PSU Proposal \# or Banner Grant \#:

F. Financial Conflict of Interest: Do any of the investigators have an economic interest in, or act as an officer or director of, any outside entity whose financial interest would reasonably appear to be affected by the results of the study? $\square$ Yes $\square$ No If yes, describe:

G. Proposed Project Duration: Anticipated Start Date: January 2020

Total Project Duration (\# of months): $\mathbf{6}$ 
H. Objectives: State the purpose and specific aims of the study; include the hypotheses to be tested or the research questions that will guide the study. Use plain language and keep description brief; suggest use of bullet points or list format.

Through the lens of adult immigrants reflecting on their schooling experience in the United States, how can schools better support the development of immigrant students? How do these experiences compare or contrast with each other? This study will aim to collect first-hand information about the immigrant experience and be a guide to shape educational programs that promote immigrant children's development.

I. Rationale: Provide the scientific or scholarly background for, rationale for, and significance of the proposed study based on existing literature and explain how it will add to existing knowledge. Briefly summarize the relevant current context of the study and gaps in current knowledge. Use plain language and keep explanation brief; suggest use of bullet points or list format.

There are studies that have collected information from immigrant children, but in this study, the participants will have a larger picture to reflect onto and be able to provide a more detailed and more experienced view of their education journey (Hajisoteriou, Karousiou, and Angelides, 2017). Past studies have shown that immigrant students benefit from efforts made to improve their well-being, development, acheivement (Dearing et al., 2016, Suárez-Orozco et al., 2010). In order to get more, specific ideas on how to improve education for immigrant students, the interviewees will provide information on what school practices they benefited or did not benefit from. By taking a step back, the investigator will get the perspectives of actual immigrant individuals who experienced education in their host country in order to get a stronger foundation for future research or interventions. This will help give greater representation to immigrant individuals and a chance to hear their voices on their educational past.

J. Subject Procedures: Briefly describe proposed study activities and indicate how project data will be gathered or generated (i.e., use of existing data, observation, surveys, interviews, experimental/control procedures, etc.). Describe how the investigator will recruit subjects to participate and explain consent/assent procedures, if applicable. 
1. Potential participants will be invited to participate in the study in one of two ways: first, the investigator will invite persons whom they have contact with; second, an invitation for voluntary participation in the study will be sent to instructors and advisors at Portland State University for distribution to student rosters (See Appendix A).

2. Once participants express interested, the investigator and the participant will schedule a meeting time for the interview. The investigator will also send them the informed consent form so they can read over it.

3. The investigator and the participant will meet at Smith Memorial Student Union at Portland State University (To ensure comfort, an alternate public location of the participant's choosing can be arranged (e.g. coffee shop, library, et cetera) and after the consent form has been reviewed and signed, the interview will begin. The investigator will digitally record the interview (with the permission of the participant).

4. The investigator will ask the participant questions (Appendix B) for up to one hour.

5. The investigator will transcribe the interview and analyze the gathered information, comparing and contrasting to each interview as well as gathering key information related to the topic.

\section{SECTION 2: HUMAN SUBJECTS RESEARCH PRE-SCREENING}

\section{A. RESEARCH DETERMINATION}

1. Is the project intended to be an investigation, a searching inquiry to gather facts, or an examination of a phenomenon?

2. Is it systematic; involving a system, method, or plan that will be employed consistently throughout data collection?

3. Are the results of the project expected to expand the knowledge base of a scientific discipline, or other scholarly field or study, and be publicly disseminated so that the results can be used to develop, test, or support theories, principles, and statements of relationships or inform policy beyond the study?

4. Will the results be applicable to a larger population beyond the site of data collection or the individual subjects? (Check "No" if the conclusions will apply only to the sample population).

If the answer to ALL questions in Section $2 A$ are NO, it is likely the project does NOT meet the federal definition of research and IRB review is not required. Email this completed form to Research Integrity at psuirb@pdx.edu for confirmation.

If the answer to ANY of the questions in Section 2A is YES, it is possible this project meets the definition of research. Additional information is required. Proceed to Section $2 B$ of this form. 


\section{B. HUMAN SUBJECTS DETERMINATION}

\begin{tabular}{|c|c|c|}
\hline 1. Will investigators use, study or analyze information (or biospecimens) about living $\mathbf{p}$ & $\underset{\text { Yes }}{\bigotimes}$ & \\
\hline $\begin{array}{l}\text { 2. Will investigators obtain information through intervention or interaction with subjects? } \\
\text { Intervention or Interaction: } \\
\text { - any communication or interpersonal contact between investigator and subject, such as using } \\
\text { in-person or online questionnaires/surveys, interviews, focus groups, observations, or } \\
\text { experimental procedures. }\end{array}$ & $\underset{\text { Yes }}{\bigotimes}$ & $\begin{array}{l}\square \\
\text { No }\end{array}$ \\
\hline $\begin{array}{l}\text { 3. Will investigators obtain, use, study, analyze, or generate identifiable private information (or } \\
\text { identifiable biospecimens)? } \\
\text { Identifiable private information: } \\
\text { - information subjects expect would not be made public, or collected within a context which an } \\
\text { individual would not otherwise expect to be observed or recorded (such as in their home), } \\
\text { AND } \\
\text { the identity of the subject is or may readily be ascertained by the investigator or associated } \\
\text { with the information. } \\
\text { Identifiable biospecimen: } \\
\text { biospecimen for which the identity of the subject is associated with the biospecimen or may } \\
\text { readily be ascertained by the investigator. }\end{array}$ & $\underset{\text { Yes }}{\bigotimes}$ & $\begin{array}{l}\square \\
\text { No }\end{array}$ \\
\hline
\end{tabular}


If the answer to ALL questions in Section $2 B$ are NO, it is likely the research does NOT meet the federal STOP definition of human subjects and IRB review is not required. Email this completed form to Research Integrity at psuirb@pdx.edu for confirmation.

If the answer to Question 1 in Section 2B is YES and either Question 2 or Question 3 are also marked YES, the research involves human subjects. Additional information is required:

- Form 1: Project Overview \& Pre-Screening is now complete; retain form for submission.

- Complete Form 2: Exemption Certification to determine if the project qualifies as exempt. NOTE: In the Revised Common Rule, previously expedited research is now exempt. 


\section{Human Research Protection Review FORM 2: EXEMPTION CERTIFICATION}

Important: Federal regulations specify that certain types of research with human subjects pose low risk to subjects and may qualify for exempt review. The research must meet certain criteria related to risk, and fall into one or more of the categories defined in the federal regulations to qualify for exemption. Complete the sections below for an initial exemption assessment of the proposed research.

\section{SECTION 1: EXEMPTION SCREENING}

1. Is the project greater than minimal risk?

Minimal risk: the probability and magnitude of harm or discomfort anticipated in the research are not greater than those ordinarily encountered in daily life or during the performance of routine physical or psychological examinations or tests

2. Would any disclosure of the human subjects' responses, including their private information, outside the research reasonably place the subjects at risk of criminal or civil liability or be damaging to the subjects' financial standing, employability, educational advancement, or reputation?

3. Will prisoners (subjects confined in a correctional or detention facility, including involuntary assignment to community-based alternatives to incarceration such as drug treatment facilities) be specifically recruited to participate in this study?

4. Will the research involve deception?

5. Will the research involve materials (data, documents, records, or specimens) that have been collected or will be collected solely for non-research purposes?

6. Will alcohol or drugs be administered to the subjects as part of the research?

7. Will biological specimens and/or blood samples be prospectively collected from participants as part of the research?

8. Will data be collected from participants using non-invasive medical procedures such as collecting blood pressure or temperature?

9. Are live fetuses considered subjects in the research (providing specimens or imaging)?

10. Is this research FDA-regulated?

\begin{tabular}{|l|l|}
\hline & \\
\hline & $\bigotimes$ \\
Yes & No \\
\hline & \\
$\square$ & $\bigotimes$ \\
Yes & No \\
\hline & \\
\hline & $\bigotimes$ \\
\hline Yes & No \\
\hline$\square$ & $\bigotimes$ \\
\hline Yes & No \\
\hline$\square$ & $\bigotimes$ \\
\hline Yes & No \\
\hline$\square$ & $\bigotimes$ \\
\hline Yes & No \\
\hline$\square$ & $\bigotimes$ \\
\hline Yes & No \\
\hline$\square$ & $\bigotimes$ \\
\hline Yes & No \\
\hline$\square$ & $\bigotimes$ \\
\hline Yes & No \\
\hline$\square$ & $\bigotimes$ \\
\hline Yes & No \\
\hline
\end{tabular}

If the answer to ANY question in Section $1 A$ is YES, the research does NOT meet the exemption requirements and does not qualify for exempt review. Do not complete this form. Complete Form 3: Initial IRB Review.

If the answer to ALL of the questions in Section $1 A$ are NO, the research MAY qualify for exempt review. Additional information is required. Proceed to Section 2 below. 


\section{SECTION 2: EXEMPTION CATEGORIES \& GENERAL CRITERIA}

Instructions: Select all exempt categories that apply to the proposed research. Leave blank any categories that do not apply. Indicate which criteria applies to the proposed research within the selected category and provide all requested follow-up information.

\section{Category 1: Education}

\begin{tabular}{|l|l|}
\hline $\begin{array}{l}\text { 1.1 Will the research be conducted in established or commonly accepted educational settings? } \\
\text { Describe the educational setting: }\end{array}$ & Yes \\
\hline $\begin{array}{l}\text { 1.2 Will the research specifically involve normal educational practices that are not likely to } \\
\text { adversely impact students' opportunity to learn required educational content or the } \\
\text { assessment of educators who provide instruction? } \\
\begin{array}{l}\text { Describe the educational practices and why the research is not likely to adversely impact } \\
\text { students or instructors. }\end{array}\end{array}$ & Yes
\end{tabular}

If the answers to 1.1 and 1.2 are "Yes" then the project may qualify for exemption under Category 1.

(Continue to next page; the rest of this page is intentionally left blank.) 


\section{Category 2: Interactions}

2.1 Will the research include only the following interactions with subjects? (select all that apply)

$\square$ Educational tests (cognitive, diagnostic, aptitude, achievement)

$\square$ Survey procedures

$\triangle$ Interview procedures

Observation of public behavior (including visual or auditory recording)

2.2 Is at least one of the following criteria true? (select all that apply):

$\bigotimes$ The information obtained is recorded in such a manner that the identity of the human subjects cannot readily be ascertained, directly or through identifiers linked to the subjects. Explain how subjects' identity will not be readily identifiable:

The names of participants will not be collected neither in the digital recording of the interview nor on the transcript. Pseudonyms will be given to the interviewees in order to protect their identity. The digital recordings, transcripts, the report, and all other project materials will be stored on a password-protected computer and the digital recording will be destroyed within one year of the interview.

Any disclosure of the subjects' responses outside the research would not reasonably place the subjects at risk of criminal or civil liability or be damaging to the subjects' financial standing, employability, educational advancement, or reputation.

Explain why disclosure of responses does not pose risks listed above:

The disclosure of the responses outside the research would not reasonalby place the subjects at risk of criminal or civil liability or be damaging to the subjects' financial standing, employability, educational advancement, or reputation because the subjects are asked about their education experience in the context of their development as an immigrant student and should not lead to any of the previously stated risks.

If disclosure of the subjects' responses outside the research would reasonably place the subjects at risk of criminal or civil liability or be damaging to the subjects' financial standing, employability, educational advancement, or reputation, there are adequate provisions to protect the privacy of subjects and to maintain the confidentiality of data.

Describe the provisions to protect the privacy of subjects and to maintain the confidentiality of data:

2.3 Is one of the following criteria true? (select only one):

$\bigotimes$ The research does NOT involve Children as subjects (under age 18).

$\square$ The research is limited to educational tests or observation of public behavior where the investigator(s) do NOT participate in the activities being observed.

2.4 Are Prisoners excluded as subjects (except for research aimed at involving a broader population that only incidentally includes Prisoners)?

repulion that only incidentally includes Prisoners ?

If the answers to questions 2.1-2.4 are "Yes" then the project may qualify for exemption under Category 2. 


\section{Category 3: Behavioral Interventions}

3.1 Will the research involve behavioral interventions in conjunction with the collection of information through verbal or written responses (including data entry) or audiovisual recording?

3.2 Will subjects prospectively agree to the intervention and information collection?

3.3 Will the behavioral interventions be brief in duration, harmless, painless, not physically invasive, and not likely to have a significant adverse lasting impact on the subjects?

3.4 Does the investigator think the subjects will NOT feel embarrassed or be offended by the interventions?

3.5 Is at least one of the following criteria true? (select all that apply):

$\square$ The information obtained is recorded in such a manner that the identity of the human subjects cannot readily be ascertained, directly or through identifiers linked to the subjects. Explain how subjects' identity will not be readily identifiable:

Any disclosure of the subjects' responses outside the research would not reasonably place the subjects at risk of criminal or civil liability or be damaging to the subjects' financial standing, employability, educational advancement, or reputation.

Explain why disclosure of responses does not pose risks listed above:

If disclosure of the subjects' responses outside the research would reasonably place the subjects at risk of criminal or civil liability or be damaging to the subjects' financial standing, employability, educational advancement, or reputation, there are adequate provisions to protect the privacy of subjects and to maintain the confidentiality of data.

Describe the provisions to protect the privacy of subjects and to maintain the confidentiality of data:

3.6 Are Children (under age 18) excluded as subjects?

3.7 Are Prisoners excluded as subjects (except for research aimed at involving a broader population that only incidentally includes Prisoners)?

If the answers to questions 3.1-3.7 are "Yes" then the project may qualify for exemption under Category 3. 


\section{Category 4: Secondary Research Without Consent}

4.1 Will the research involve the use of Identifiable Private Information or Identifiable Biospecimens without obtaining consent?

4.2 Is one of the following criteria true? (select all that apply)

$\square$ The Identifiable Private Information or Identifiable Biospecimens are publicly available. List the source of the information, how the information is will be accessed and what will be recorded. Include in the response if a data use agreement or special permission is required to access the data:

The information (including information about biospecimens) is recorded by the researcher in such a manner that the identity of the human subjects cannot readily be ascertained directly or through identifiers linked to the subjects, the investigator does not contact the subjects, and the investigator will not re-identify subjects.

List the source of the information, how the information will be accessed and what will be recorded by the investigator. Include in the response if a data use agreement or special permission is required to access the data:

The research involves only information collection and analysis involving the investigator's use of identifiable health information when that use is regulated under the Health Insurance Portability and Accountability Act (HIPAA) for the purposes of health care operations or research.

List the source of the information and how it will be accessed:

What permission is required to access the data:

$\square$ HIPAA Authorization
$\square$ Waiver of Authorization
$\square$ Data Use Agreement
$\square$ Other; describe:

The research is conducted by, or on behalf of, a Federal agency using governmentgenerated or government-collected information obtained for non-research activities, if the research generates identifiable private information that is or will be maintained on information technology that is subject to and in compliance with the E-Government Act.

4.3 Are Prisoners excluded as subjects (except for research aimed at involving a broader population that only incidentally includes Prisoners)?

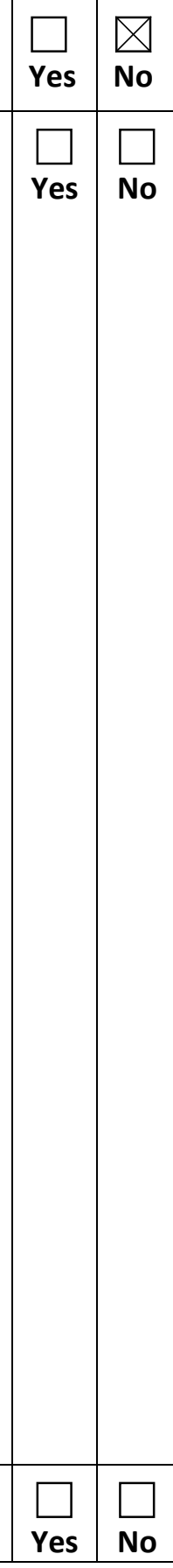

If the answers to questions 4.1-4.3 are "Yes" then the project may qualify for exemption under Category 4.

(Continue to next page; the rest of this page is intentionally left blank.) 


\section{Category 5: Federal Demonstration Projects}

5.1 Will the research or demonstration project be conducted or supported by a Federal department or agency, or otherwise subject to the approval of department or agency heads?

List the federal agency:

5.2 Will the research or demonstration project be designed to study, evaluate, improve, or otherwise examine public benefit or service programs, including procedures for obtaining benefits or services under those programs, possible changes in or alternatives to those programs or procedures, or possible changes in methods or levels of payment for benefits or services under those programs?

List name of public benefit or service program:

5.3 Will the research or demonstration project be published on a list of research and demonstration projects exempted under this category prior to commencing the research?

5.4 Are Prisoners excluded as subjects (except for research aimed at involving a broader population that only incidentally includes Prisoners)?

If the answers to questions 5.1-5.4 are "Yes" then the project may qualify for exemption under Category 5.

\section{Category 6: Taste and Food Quality Evaluation and Consumer Acceptance Studies}

6.1 Will the research involve taste and food quality evaluation and consumer acceptance studies where wholesome foods without additives are consumed, or food is consumed that contains a food ingredient at or below the level and for a use found to be safe, or agricultural chemical or environmental contaminant at or below the level found to be safe, by the Food and Drug Administration or approved by the Environmental Protection Agency or the Food Safety and Inspection Service of the U.S. Department of Agriculture? List the foods to be used in this study:

6.2 Are Prisoners excluded as subjects (except for research aimed at involving a broader population that only incidentally includes Prisoners)?

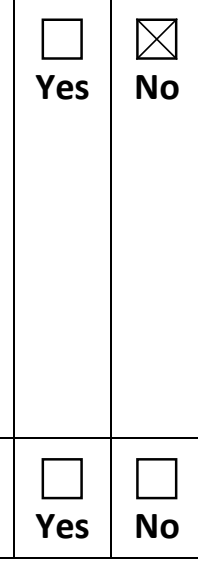

If the answers to questions 6.1 and 6.2 are "Yes" then the project may qualify for exemption under Category 6.

Categories 7 \& 8: These exemption categories, as outlined in 45 CFR 46.104, require additional consent provisions and tracking requirements. Research in these categories is not eligible for exemption at this time. 


\section{SECTION 3: Protocol Submission}

To request an exemption determination for the proposed research, email the PSU Office of Research Integrity at hsrrc@pdx.edu with the following completed materials attached (check all that apply):

$\bigotimes$ Form 1: Project Overview \& Pre-Screening (completed in Step 1)

$\bigotimes$ Form 2: Exemption Certification (this form)

$\bigotimes$ Form 4: Investigator Assurance

$\bigotimes$ Consent Materials (not required for Category 4)

$\square$ Data Use Agreement(s) (or other documentation of special permission)

$\bigotimes$ Other; describe:

\section{Appendix A: Email Flyer}

\section{Appendix B: Interview Guide}

If none of the above exemption categories are applicable, the study must be reviewed by the IRB and further information is required. Complete Form 3: Initial IRB Review. 


\section{Human Research Protection Review FORM 4: INVESTIGATOR ASSURANCE}

Important: The Principal Investigator (and Student Investigator) must review each of the investigator responsibilities outlined below and check each box when understood. Each box must be checked in order for the submission to be processed by ORI.

\section{SECTION 1: INVESTIGATOR RESPONSIBILITIES}

1. I understand PSU's policies concerning research involving human subjects and that I have ultimate responsibility for the protections of the rights and welfare of human participants, the conduct of this study, and the ethical performance of this research.

2. I will maintain IRB related documents (including signed consent forms, as applicable) for a minimum of three years after the completion of the study, or for a minimum of five years after completion if the study is funded (this may vary depending on the funding agency requirements).

3. I understand it is my responsibility to ensure that all study personnel receive the mandatory human subjects' research protection education (CITI Training) and to maintain a training documentation file.

4. I agree to:

- Comply with all PSU HRPP policies, decisions, conditions and requirements.

- Obtain prior approval from the IRB before amending or altering the research protocol or changing the approved consent/assent form.

- Notify the Office of Research Integrity of any related financial conflict not already disclosed.

- Notify the Office of Research Integrity (and when applicable, the granting agency) of all adverse events, unanticipated problems, or protocol deviations in a timely manner.

5. I certify that:

- This research will be conducted in accordance with the principles of The Belmont Report.

- The time and resources are available to complete this project.

- The equipment, facilities, and procedures to be used in this research meet recognized standards for safety.

- New information that may affect the risk-benefit assessment for this research will be reported to the Office of Research Integrity.

- Adequate supervision of all research study personnel will be ensured.

- The information provided in this application and all attachments is complete and correct.

\section{SECTION 2: INVESTIGATOR SIGNATURES}

By signing below, the Principal Investigator (and Student Investigator, if applicable) agrees to the list of requirements detailed in the assurance above. PLEASE TYPE NAME BELOW.

Principal Investigator/Faculty Advisor: Rebecca Summer

Date: 11/14/2019

\section{Student Investigator: Kayla Guerrero}

Date: 11/14/2019 


\section{Human Research Protection Review \\ WAIVER OR ALTERATION OF CONSENT}

Important: Complete this form ONLY if the project involves waiving consent or altering required components of consent (removing required elements of consent or the use of deception). The regulations require obtaining consent and explaining all required elements of consent, except in cases where specifically approved by the IRB.

\section{SECTION 1: TYPE OF REQUEST (select all that apply)}

A. This request is for complete waiver of informed consent. Yes $\bigotimes$ No A.1. Describe the population(s) that will not participate in an informed consent process.

\section{A.2. Provide a justification for the rationale behind waiving the entire informed consent process.}

B. This request is for alteration of informed consent (e.g., removing some of the required elements of consent or using deception in research).

B.1. Describe the population(s) that will participate in the altered informed consent process:

All of the partcipants.

B.2. Detail the specific elements of consent that will be altered or removed from the informed consent process.

The participants will give verbal consent instead of signing the form. This will be audio-recorded before the interview begins.

B.3. Provide a justification for the rationale behind altering the informed consent process to not include all of the required elements of informed consent.

Because this study will include both documented and undocumented immigrants, we want to take all precautions in protecting undocumented immigrants' identity, so their signature cannot be traced back to them and possibly have their documentation status exposed if in the unlikely event that their private information was leaked. This way, there would be no connection to the undocumented participants, therefore they would not be at risk for exposure of their documentation status if confidentiality is breached. The interviewer will not directly ask the participant their documentation status, but that 
doesn't mean that the participant won't divuldge that information themselves (Hernández, Nguyen, Casanova, Suárez-Orozco, \& Saetermoe, 2013).

\section{SECTION 2: CONDITIONS FOR IRB APPROVAL}

A. This research involves no more than minimal risk to subjects. $\bigotimes$ Yes $\square$ No Explain how this condition is met:

The participants will be getting interviewed and asked to reflect back on their education experience as an immigrant in the United States, so the only minimal risk is that reflecting back may bring bad memories to surface, possibly causing mild discomfort. If this happens, the investigator will provide resources to help the participants.

B. This research could not practicably be carried out without a waiver or alteration.

$\bigotimes$ Yes $\square$ No Explain how this condition is met:

If a breach of confidentiality happens, the possible undocumented immigrant participants could be at risk of having their documentation status exposed and possibly getting deported. The only identifiable information could connect the undocumented immigrants to their status is their signature, so if the particpants all got verbal consent, the undocumented participants will have zero identifiable information and would be extra protected in case of a breach.

C. If the research involves using identifiable private information (or identifiable biospecimens), the research could not practicably be carried out without using such information in an identifiable format. $\square$ Yes $\square$ No $\$ N/A

Explain how this condition is met:

D. This waiver or alteration will not adversely affect the rights and welfare of the subjects.

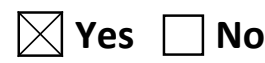

Explain how this condition is met:

This study's purpose is exploratory on the experiences of immigrants in education through interviews, so giving verbal consent will not affect the rights and welfare of the participants.

E. Whenever appropriate, the subjects or legally authorized representatives will be provided with additional pertinent information after participation (e.g., provided with a debriefing, counseling services, etc.). 
Explain how this condition is met:

If the participants during the interview feel discomfort from speaking about their school experiences, the investigator will assist the participant in seeking a counselor or to other resources that will help them.

F. This research is not subject to FDA oversight. 
Dear

My name is Kayla Guerrero, and I am an undergraduate psychology student in the Urban Honors College at Portland State University. I am conducting a research project about the development of immigrants in education with Assistant Professor Dr. Rebecca Summer of the Urban Honors College at Portland State University.

I am searching for about five possible individuals to participate in my research project. You will be asked questions in an interview that will last up to one hour. Your name or any other identifiable information will be confidential.

The interview will consist of asking you to reflect back on your education experience as an immigrant child and think about how the school system either supported or hindered your development.

In order to participate, you must meet the following requirements:

- An immigrant or at least one parent is an immigrant

- Entered school in the United States before the fifth grade

- $18+$

If you meet these requirements and are interested in being a part of this study, please reply to this email so we can set up an interview date.

Thank you for your consideration and I hope to hear from you! Your help will be much appreciated.

If you have any further questions please feel free to contact me (Kayla Guerrero ukayla@pdx.edu) or my advisor at (Rebecca Summer - rebeccasummer@pdx.edu)

Best,

Kayla Guerrero 


\section{Consent to Participate in Research}

Project Title: The Development of Immigrant Students in Education

Population:

Researcher:

Researcher Contact: Kayla Guerrero: ukayla@pdx.edu

Rebecca Summer: rebeccasummer@pdx.edu

You are being asked to take part in a research study. The box below highlights the main information about this research for you to consider when making a decision whether or not to join in the study. Please carefully look over the information given to you on this form. Please ask questions about any of the information you do not understand before you decide to agree to take part.

\section{Key Information for You to Consider}

- Voluntary Consent. You are being asked to volunteer for a research study. It is up to you whether you choose to take part or not. There is no penalty if you choose not to join in or decide to stop your involvement.

- Why is the study being done? The reason for this research is to explore the stories of immigrant children in education and how that affects their development (psychological growth). This will act as a guide for future researchers to know what immigrant students need and what is important for their well-being at school, and eventually apply programs, activities, provide resources to immigrants and their families in order to make the adjustment to schooling much easier.

- How long will it take? Your participation should last about one hour, but you may take breaks as needed.

- What will I be expected to do? You will be asked to...

1. Read over this consent form and agree if you would like to.

2. Be involved in an in-person interview that will be recorded digitally.

3. You will be asked questions about your life story as an immigrant student, skipping any questions you do not feel comfortable answering. You should answer questions honestly and with as much detail as you want.

- Risks. Some of the possible risks or discomforts of taking part in this study include feeling slight discomfort when talking about your schooling past if it was not a pleasant time for you. If you feel this discomfort, let the researchers know so they can show you resources to get help.

- Benefits. No direct benefit but the researchers hope to learn about the experiences of immigrants from immigrants themselves, and hope to understand ways to start making school a better place for immigrant students.

- Options. Participation is voluntary and the only alternative is to not participate.

\section{What happens to the information collected?}

Information collected for this research will be used to form a thesis research project that may be published. Although, information that connects you to your identity will not be included. 


\section{How will my privacy and data be protected?}

We will take measures to protect your privacy including assigning you a pseudonym (a made-up name), and not collecting any information that connects you to your identity. You will remain anonymous in this research project. We will keep the digital recordings, transcripts of your interview, and all other study materials on a passwordprotected computer. Your digitally recorded interview will be destroyed within one year of your interview date. Despite taking steps to protect your privacy, we can never fully guarantee that your privacy will be protected.

Only the student investigator will have access to your digitally recorded interviews. Your name or identity will NOT be used for publication or publicity purposes.

Individuals and organizations that conduct or monitor this research may be permitted access to inspect research records. These individuals and organizations include the Institutional Review Board that reviewed this research and the student investigator.

Both documented and undocumented immigrants are welcome to participate in this study, but the investigator will not ask your documentation status. However, if you decide to say your documentation status on your own terms, we will take extra protections to make sure you will be disconnected from information that may identify you. These extra protections include you being asked to verbally consent versus signing this form in order to remove all information that connects you to your identity (your signature) in case you are undocumented.

\section{What if I want to stop my part in this research?}

Your part in this study is voluntary. You do not have to take part in this study, but if you do, you may stop at any time. You have the right to choose not to take part in any study activity or completely stop at any point without penalty or loss of benefits to which you are otherwise entitled. Your decision whether or not to join in will not affect your relationship with the researchers or Portland State University.

\section{Will I be paid for being in this research?}

You will not be paid for being in this research study.

\section{Who can answer my questions about this research?}

If you have questions, concerns, or have experienced a research related injury, contact the research team at:

Kayla Guerrero
Email: ukayla@pdx.edu

Rebecca Summer

Email: rebeccasummer@pdx.edu

\section{Who can I speak to about my rights as a part of research?}

The Portland State University Institutional Review Board ("IRB") is overseeing this research. The IRB is a group of people who independently review research studies to ensure the rights and welfare of participants are protected. The Office of Research Integrity is the office at Portland State University that supports the IRB. If you have questions about your rights, or wish to speak with someone other than the research team, you may contact: 
Portland, OR 97207-0751

Phone: (503) 725-5484

Toll Free: 1 (877) 480-4400

Email: psuirb@pdx.edu

\section{Consent Statement}

I have had the opportunity to read and consider the information in this form. I have asked any questions necessary to make a decision about my taking part in the study. I understand that I can ask more questions at any time.

By speaking the line below, I understand that I am volunteering to take part in this research. I understand that I am not waiving any legal rights. I have been provided with a copy of this consent form. I understand that if my ability to consent for myself changes, either I or my legal representative may be asked to provide consent before I continue in the study.

Speak this: I consent to join in this study.

Check the box that applies:

I consent to join in this study

I do not consent to join in this study. 


\section{Interview Guide}

HRPP \#: $196745-18$

- Have the interviewer review the consent document with the interviewee and take the time for the interviewee to ask any questions.

- Before we get started, I need to make sure you understand the consent form and answer any you have questions you may have. There is copy for you to keep and a copy that I need with your signature if you decide to give consent to participate. Remember that this is voluntary and if you do not wish to participate AT ANY TIME, you can withdraw from the conversation and/or not answer a particular question.

- Collect signed Consent Form

- After the participant has provided consent, the interviewer will ask for consent to start digitally recording.

$\circ$ Let the participant know that you will be recording the conversation and that their name will not be used in any of the written transcript data. Ask if you may record the conversation - wait for affirmation from the participant.

1. What are some positive aspects of school that helped you adjust to school in the United States as an immigrant student?

a. Were you able to make friends? Did they help you out?

b. How did your family help?

c. How helpful were the teachers/other staff at the school?

d. Did your school have any special events or programs that helped you or your family?

e. Did your teacher or school try to integrate your culture into the curriculum or school events?

2. What are some challenges you faced as an immigrant student in your first few years of school in the United States?

a. What were some things that made you feel uncomfortable at school?

b. Things that made you feel unwelcome? Excluded?

c. What was something that you really needed, but never got?

3. Were you able to communicate with your peers/teacher?

a. Did you learn English at school?

4. If you were to volunteer or work in a classroom that had new immigrant children, what would you do to help those children succeed?

a. Who were the people who helped you in school?

5. What is something you would change about the way your school helped (or didn't help) you transition to schooling in the United States?

a. Why? 